\title{
5. \\ INTELEKTUALIZAM TRANZICIJE I TRANZICIJA INTELEKTUALIZMA: PRIMJER LJUBLJANSKE NOVE REVIJE
}

\section{Ivana Latković}

UDK: 070.48(497.4):008

Sažetak: Analizom doprinosa ljubljanske Nove revije polju intelektualnog djelovanja i angažmana osamdesetih i devedesetih godina u Sloveniji, u radu će se nastojati prikazati kako su autori, prije svega iz književne sfere, razumijevali vlastitu poziciju intelektualca, funkcije i zadaće svoga rada, kao i pretpostavke njegova djelokruga. Na temelju objavljenih tekstova i usmenih istupa autora kao što su Niko Grafenauer, Rudi Šeligo, Marjan Rožanc, Dimitrij Rupel, Drago Jančar, nastojat će se osvijetliti njihova viđenja smisla i uloge intelektualnog djelovanja u vrijeme tranzicije, i to prije svega u okviru razlikovanja njegove participacije $u$ dnevnoj politici, uloge u razvoju neovisnih institucija i (de)legitimiziranja postojećih odnosa moći u vrijeme pokretanja Nove revije i danas.

Ključne riječi: Nova revija, književnici intelektualci, tranzicija, javni angažman, kultura i politika

(?) bogatoj slovenskoj tradiciji književnih i kulturnih časopisa ljubljanska Nova revija nedvojbeno zauzima važno mjesto i predstavlja jedinstvenu pojavu u mnogočemu pionirskog značaja i djelovanja. Još od samih početaka njezine su objave izazivale žive reakcije i burne reperkusije, dakle još tamo od 1980. godine kada se pojavila zamisao o njezinu osnivanju i 1982. kada je konačno pokrenuta, preko legendarnog 57. broja 1987. godine kao i u izdanjima iz devedesetih godina, pa sve do danas kada je na različite načine još uvijek prisutna u slovenskome javnom prostoru. Tako će 2003. godine, povodom jubilarnih dvadeset godina postojanja Nove revije, Iztok Klemenčič u Mladini napisati da se mnogi užasnu na spomen samog imena Nova revija, jer za neke ono znači leglo slovenske desne inteligencije, drugi pak na nju gledaju s cinične distance kao na klub neurotičnih ljubitelja alkoholnih pića, dok je za treće ona Biblija u obliku zapisa vodeće slovenske kulturne i znanstveno-filozofske inteligencije. ${ }^{1}$ Ovako ili onako, u Novoj reviji radove su objavljivali brojni slovenski intelektualci, kao i oni iz drugih područja bivše države, stavovi nekih od njih kasnije su kulminirali u tezama za slovenski nacionalni program, ali i u onima za slovenski ustav, kao i u osnivanju Demosa, odnosno na prvim demokratskim

1 Iztok Klemenčič, "Več kot le revija" (http://www.mladina.si/97608/). 
izborima izabrane koalicije stranaka. Iz ovoga je već jasno kako Nova revija nije bila samo mesečnik za kulturo, kako stoji u nastavku naziva. Već je i u inicijativi za pokretanje revije i $s$ prvim objavljenim brojem bilo jasno da će ona obuhvatiti puno širi društveni horizont ${ }^{2} \mathrm{i}$ da se neće ustezati od gorućih političkih pitanja i tema, dapače, kultura i politika u Novoj reviji bile su nerijetko neraskidivo povezane. Uvjerljiv argument tomu i sukus takva koncepta možemo pronaći u riječima jednog od protagonista svih važnijih događaja vezanih uz Novu reviju, Dimitrija Rupela, koji možda ponajbolje utjelovljuje istovremenu praksu tih dviju sfera. Rupel, naime, kao jedan od glavnih inicijatora i kasnijih suradnika časopisa 2002. godine u časopisu Ampak pomalo pojednostavljeno rezimira.

Iz kulturne revije nastao je politički program koji se je, takoreći, u cijelosti ostvario. Prvo smo osnovali stranke koje su sve redom poduprle Majnišku deklaraciju iz 1989. godine, ${ }^{3}$ potom smo izašli na izbore i došli u vladu. Zbog spora i rata s Jugoslavijom sklopili smo pakt $s$ komunistima s kojima kohabitiramo još i danas. Ipak, unatoč svemu Nova revija bila je velik uspjeh. Na njezinoj podlozi osnovali smo državu koja je, zapravo, vrlo uspješna. (...) Nova revija danas živi u Ustavu, u državnom parlamentu i u vladi. Nova revija će nas na koncu dovesti u Europsku uniju i NATO. ${ }^{4}$

Od samih početaka revije na njezinim su stranicama objavljivali ne samo kulturnjaci već i političari, od ministara, predsjednika političkih stranaka, slovenskog parlamenta, saborskih zastupnika itd., što se je, dakako, uvelike odrazilo na konceptualnu i idejnu platformu samoga časopisa. No, ovom prilikom pažnja će ipak više biti usmjerena na literateintelektualce kojih je u Novoj reviji bilo nemali broj, što u uredništvu, što kao autora u njoj objavljenih tekstova. Već je u inicijativi za pokretanje časopisa bio niz uglednih književnih imena kao što su: Petar Božič, Milan Dekleva, Branko Gradišnik, Niko Grafenauer, Drago Jančar, Milan Jesih, Dušan Jovanović, Lojze Kovačič, Svetlana Makarovič, Boris A. Novak, Marjan Rožanc, Dimitrij Rupel, Ivo Svetina, Rudi Šeligo, Veno Taufer, Dane Zajc itd. Ovakav selektivni pristup nije vođen samo mojom osobnom preferencijom i strukom, već i činjenicom da je figura literata-intelektualca gotovo oduvijek svojevrsna konstanta slovenskoga javnog života, što, dakako, nije slovenska posebnost. U prilog tomu svakako ide činjenica da su do početka 20. stoljeća jedini obrazovani ljudi u Sloveniji, uz svećenike, uglavnom bili književnici koji su na sebe preuzeli ulogu "glasnika kritičke svijesti" (Ko$\left.m^{5} l^{5}\right)$ i tako postali glavni nositelji analitičkoga rezoniranja u najširem smislu društvenih problema.

U tom smislu književni su se intelektualci odredili kao zasebna skupina u javnoj sferi društva, i to upravo onako kako je Charles Percy Snow u svojoj poznatoj knjizi The Two Cultures (1959.) naveo. Naime, ondje autor razlikuje dvije temeljne skupine unutar intelektualne jezgre društva, jednu čine književni intelektualci, a drugu znanstvenici (prirodnih znanosti). Snow ovdje, zapravo, kritizira pomanjkanje komunikacije između tih skupina, proizašlo iz pretjerano svojeglavog inzistiranja na vlastitom iskustvu, stavovima, navikama

2 Primjerice, u prvom broju Ivan Urbančič objavljuje tekst pod naslovom Nekaj skic za začetek Nove revije u kojem gotovo herderovski prikazuje jezik kao "prafaktički etnički element slovenstva”, utemeljujući time nacionalnu ideju na relaciji jezik - kultura.

3 Majnišku deklaraciju formulirale su slovenske opozicijske stranke 1989. godine i u njoj su zahtijevale suverenu državu slovenskoga naroda. Na Kongresnom trgu u Ljubljani pročitao ju je Tone Pavček.

4 Dimitrij Rupel, "Nova revija, nov tednik, nova televizija”, Ampak, 3/2002., br. 6-7, 7-8.

5 Dean Komel, "Kritična beseda v tem času?”, Dialogi, 38/2002., br. 3-4, 33. 
i idejama, čiju štetu na koncu snosi cjelokupno društvo u kojem oni javno djeluju. ${ }^{6}$ Međutim, u ovome kontekstu ipak se čini važnija činjenica da su literati-intelektualci već odavna prepoznati kao zasebna skupina javne intelektualne scene koja nosi specifična i zasebna obilježja u odnosu prema drugim tipovima intelektualca, pa u skladu s time i vlastita načela javnog djelovanja i angažmana. U kontekstu novorevijaša, ali i ne samo njih, ta su načela, dakako, neraskidivo povezana s društvenim i političkim okolnostima unutar kojih su djelovali, posebice u kontekstu njihovih tektonskih promjena devedesetih godina.

Upravo na tragu toga često se može naići na stav kako su literati-intelektualci, uz svoj tradicionalno privilegirani status, u komunističkom režimu bili u ponešto povoljnijoj poziciji od, primjerice, sociologa ili povjesničara (naravno, kao itekako uvjerljiv protuargument ovdje se može spomenuti disidentska književnost, ali ostavimo to ovom prilikom po strani) jer su, tobože, imali više slobode i/ili a priori nisu uzimani kao relevantni interpretatori duha vremena. ${ }^{7}$ Nerijetko je potonje blisko povezano s onim viđenjima književnikaintelektualaca, i danas itekako prisutnim, kao onih koje je "nerijetko vodila žeđ za senzacijom iznikla iz književnog i pjesničkog imaginarija, te vlastite osobne doživljajnosti", "oni su bili izmišljatelji, oni koji fantaziraju" ${ }^{8}$ ili, kako kaže Bernard Nežmah, kao književnici oni nisu bili kritičari, odnosno oni koji negiraju postojeće, već samo autori paralelnih književnih svjetova. ${ }^{9}$ Razloge, barem neke od njih, veće propusnosti misli književne inteligencije u sferu javnoga u vrijeme komunističkog režima sasvim sigurno moguće je pronaći u strategija ma svojevrsnog delegitimiranja kredibiliteta književnika-intelektualca. No, mogli bismo reći kako je to u kontekstu Nove revije iskorišteno upravo za proboj u sferu javnoga. Upravo su ondje među intelektualcima književnici bili ti koji su artikulirali i iznijeli neka ključna društvena i politička pitanja toga vremena. Uvelike je tomu pripomogao već spomenuti, tradicijom potvrđeni, privilegirani status književnika-intelektualaca, koji se ukratko može objasniti i riječima Matevža Tomšiča koji u svome tekstu Med kulturo in politiko: dileme vzhodno-in srednjeevropskih intelektualcev na poti "vračanja v Evropo" (inače, riječ je o tekstu objavljenom upravo u Novoj reviji) piše kako je za srednjoeuropski prostor karakteristično da se stalno ugrožena nacionalna egzistencija zbog krhkosti političkih institucija brani i čuva kulturom, posebice književnošću.

Nadalje, ističe Tomšič, u slovenskom je primjeru to još ponešto izraženije.

$\mathrm{Tu}$ (U Sloveniji - op. I. L.) je riječ o razlikama u poimanju odnosa između umjetnosti i drugih društvenih područja - prije svega politike, te o samom odnosu prema komunističkom režimu. Ugrubo bi se mogla razlikovati dva pogleda na odnos umjetnosti prema društvenopolitičkoj stvarnosti: angažirani i neangažirani; pri tome je angažiranost umjetnosti razumljena u smislu njezina opredjeljenja za neke neumjetničke zadaće, za ostvarenje pojedinih društvenih i političkih projekata. To u Sloveniji ima dugu tradiciju, povezano je s pojavom tzv. "slovenskog kulturnog sindroma", ${ }^{10}$ po kojem kultura vrši funkcije koje su obično u domeni politike i njezinih aktera. Takav koncept angažirane kulture predstavljala je tradicija

6 Charles Percy Snow, The two cultures and the scientific revolution, New York 1961., 4-5 i dalje.

7 Usp. Rok SvetLIČ, “Teza o prednosti literatov pri javnem angažmaju in družbeni vlogi”, Dialogi, 38/2002., br. 3-4, $38-43$.

8 Cvjetko Milanja, Čemu intelektualci u postmoderno doba, Zagreb 2011., 19, 29.

9 Bernard NežmaH, "Slovenski intelektualec, literat-intelektualec in medijski intelektualec", Dialogi, 38/2002., br. $3-4,36$.

10 Izvorno je riječ o konceptu D. Pirjevca nazvanom "prešernovska struktura” iz 1969. godine i tzv. "slovenskom kulturnom sindromu” D. Rupela iz 1976. godine. Njima autori razumiju povijesnu posebnost slovenske književnosti proizašlu iz njezine funkcije nadomještanja političkih, ali i drugih institucija ovjere nedržavnog i podređenog naroda. 
kulturnih časopisa kao što su Beseda, Revija 57, Perspektive, sve do Nove revije. Upravo potonja predstavlja vrhunac političke angažiranosti intelektualaca. (...) Postojali su i zagovornici politički neangažirane kulture. Ovdje pripadaju npr. pogledi inicijatora revije Katalog krajem šezdesetih godina (...). ${ }^{11}$

Uz to, nerijetko je vidljivo da su intelektualci iz književnog kruga itekako svjesni vlastite pozicije u društvu kojem pripadaju, zbog čega su se do krajnjih granica znali usprotiviti upornoj marginalizaciji njihova angažmana.

Samopercepcija slovenskog literata s obzirom na vlastitu društvenu ulogu vjerojatno je stigmatizirana time da percipira svoje poslanstvo već u posredovanosti s poslanstvom svog ceha: u jeziku i književnosti vidi temelj opstanka naroda, u svom vlastitom djelovanju povijesni čin. (...) Iz takva samorazumijevanja osjeća, takoreći, kao svoju dužnost da poseže u politička, društvena i povijesna događanja. ${ }^{12}$

Ako je sve navedeno bilo, kao svojevrsna pretpostavka djelovanja, uključeno u angažman književnika intelektualaca oko Nove revije od samih njezinih početaka pa do kulminacije 1987. godine (kada je objavljen slovenski nacionalni program), onda se kao sasvim logično nameće pitanje što se sa svime time dogodilo kada se je taj veliki plan o samostalnoj Sloveniji konačno ostvario, odnosno kako je to utjecalo na njihovo razumijevanje vlastite pozicije intelektualca, kako su u novim okolnostima vidjeli svoju ulogu i javni angažman, te, na koncu, što je nadomjestilo njihovu tradicionalnu ulogu zagovaratelja i čuvara nacionalnog identiteta. Zanimljive su u tom smislu riječi Nike Grafenauera povodom dvadesete obljetnice izlaženja Nove revije i pitanja koja on postavlja o njezinoj budućnosti. Grafenauer, naime, kaže da Nova revija mora

(...) prihvatiti nove izazove, ali i odgovornost koja je povezana prije svega s činjenicom da ulazimo u europske i druge međunarodne asocijacije ne znajući odgovore na ona pitanja koja se tiču temeljnih vidika našeg individualnog i zajedničkog življenja. Što danas određuje slovenski identitet? Kako na njega utječu sadašnja politička i gospodarska događanja? (...) Što je s druge strane s odnosom države i vlasti prema kulturi kao nositeljici nacionalnog identiteta? ${ }^{13}$

Dakle, gotovo da su posrijedi stara pitanja u novo vrijeme. Na tragu toga piše i Veno Taufer koji konstatira kako je intelektualno javno angažiranje njegova "ceha" izgubilo na glasnosti, što je u redu, kaže Taufer, jer "više nije riječ o tzv. egzistencijalnoj nacionalnoj ugroženosti”, već su posrijedi "parcijalni problemi, stiske” koje se odnose na konkretne struke, ali u tom smislu parcijalnost je uvijek istovremeno problem i za cijelu državu, "[d]rugim riječima: svaki unutarnji ili vanjski problem sada je problem cijele države, njezine samosvijesti, samostalnosti, međunarodnog odnosa ili pak 'pravne države”. Kao goruće probleme danas Taufer navodi pitanje prodaje slovenskih banaka, pitanje jednakopravnosti slovenskog kao službenog jezika EU-a, problem "mekane” zapadne granice, pitanje manjina, servilnosti politike prema iznuđujućim susjedima i birokratima EU-a itd. Uz to, Taufer kritizira svoje kolege da su (na koncu ipak) platili preveliki danak i lijevoj i desnoj političkoj opciji. ${ }^{14}$

11 Matevž Toмšıč, "Med kulturo in politiko: dileme vzhodno- in srednjeevropskih intelektualcev na poti 'vračanja v Evropo", Nova revija, 22/2003., br. 252-253, 305.

12 Boris VezJaK, "Uvodnik (Literati proti neliteratom: O javnem angažmaju in družbeni vlogi literatov-intelektualcev v primjeravi z neliterati-intelektualci)", Dialogi, 38/2002., br. 3-4, 19.

13 Niko Grafenauer, "Nova revija in izzivi časa”, Ampak, 3/2002., br. 6-7, 8.

14 Veno TAufer, "Slovenski intelektualec na poti iz 20. v 21. stoletje”, Dialogi, 38/2002., br. 3-4, 47. 
$\mathrm{Na}$ tragu toga, rekli bismo, svako vrijeme nosi svoje (velike) probleme i zato nije nevažno tko ih predstavlja i kako to čini. Godine 1998. u Novoj reviji objavljen je razgovor u njezinu uredništvu u kojem su, među ostalima, sudjelovali Niko Grafenauer, Dimitrij Rupel, Boris A. Novak, Rudi Šeligo, Ivo Svetina, Drago Jančar i dr. Prvo pitanje koje Grafenauer kao poticaj za razgovor postavlja bilo je: "Što je Nova revija bila nekada u bivšem režimu i što je danas?” Kako se većina sugovornika kasnije referirala na njega, citirat ću najprije odgovor D. Rupela.

S Novom revijom ušli smo u središte slovenske kulture. Kada smo ušli u to središte, zbog posebnih slovenskih okolnosti i uzusa, koje sam nekoć nazvao "slovenski kulturni sindrom" ušli smo u središte naroda. U središtu naroda uspjeli smo stvoriti slovensku državnost. Nova revija bila je važan čimbenik toga stvaranja.

Svoje djelovanje započeli smo u vrijeme kada je kultura bila središte naroda. Iz mnogih razloga [i obzira] politiku smo nadomještali kulturnim djelovanjem. Kulturnim sredstvima dosegnuli smo političke ciljeve. (...) Danas je središte naroda politika. (...)

U 57. broju Nove revije u središte svog kulturnog djelovanja, koje je zapravo bilo politička akcija, postavili smo naciju. Ali sada se priča, odnosno posao nastavlja. Slovenija je europska nacija u tranziciji. Postaje, naime, moderna europska nacija, a moderne se europske nacije organiziraju u EU. Pri tome se bude strahovi i sumnje vezane za suverenost nacija i njihov identitet. $^{15}$

Na ove Rupelove riječi replicira Boris A. Novak ne slažući se s njime da je kultura u prošlosti uvijek bila samo centar nacije. Ona je za Novaka bila neka vrsta eks-centra, odnosno ekscesa koji se je uvijek iznova selio u centar. I ono što je još važnije, za Novaka takva "optimistična vizija kulture kao centra nacije i državotvornosti danas više nije važeća”, uz to "ne samo da je kultura gurnuta na rub, već je na neki način izašla izvan državnih okvira". ${ }^{16}$ Upravo ova Novakova misao o potpunoj marginalizaciji kulture, u ovome kontekstu i intelektualaca, prevladavajuća je u današnjim stavovima intelektualaca o vlastitoj poziciji i djelovanju u društvu. Naime, neosporno je da su u tranziciji, dakle u vrijeme suočenja s brojnim postsocijalističkim konfuzijama, intelektualci politički marginalizirani, odnosno da je uloga intelektualca promijenjena u stupnju političke participacije u dnevnoj politici. Kako ističe već spomenuti Matevž Tomšič,${ }^{17}$ nakon demontaže starog režima brojni su se intelektualci našli u nezavidnom položaju, prije svega u kontekstu svojega odnosa prema politici, i to u dilemama kako se postaviti naspram konkretne političke angažiranosti. Oni koji su se odlučili na javni politički angažman morali su se, ili su se barem trebali, zapitati nad svojim intelektualnim poslanstvom i suočiti se s raznovrsnim praktičnim kalkulacijama. S druge pak strane, ističe Tomšič, odvijala se svojevrsna "depolitizacija" intelektualaca u smislu njihova odmaka od političkih institucija, što je značilo oprostiti se od strateških odluka u društvu i za društvo. Naravno, bilo je ovdje i puno hoda u sivoj zoni, negdje između ovih dviju opcija. Za precizniji smještaj intelektualaca u tranziciji spomenut ću ovdje jednu moguću tipologiju, onu koju navodi Peter Zajac i prema kojoj su moguća četiri tipa intelektualca nakon pada komunizma: prvi su oni kojima su politika i kultura oduvijek bile krajnje nepomirljive i nespojive, oni su svoje poslanstvo intelektualca oduvijek vidjeli kao djelovanje za dobrobit društva kojem pripadaju; drugi je tip onaj koji je zbog razočaranja i

\footnotetext{
5 "Nova revija in izzivi časa", Nova revija, 17/1998., br. 199-200, 4-5.

16 Isto, 11.

17 M. Tомšı̌́, "Med kulturo in politiko", 305.
} 
opće rezignacije koju je donijela tranzicija zauvijek napustio politiku; treći tip intelektualca predstavljaju oni koji su zbog svojih političkih sposobnosti ostali u politici (njih je najmanje); četvrti tip čine intelektualci koji su s novom demokracijom ušli u vlast, ali su iz nje bili izbačeni; neki od njih pokušali su se vratiti u politiku, neki su njome pokušali manipulirati iz pozadine itd. ${ }^{18}$

Kojim su putem krenuli novorevijaši? Kao što smo vidjeli, primjerice, Grafenauer i Taufer bliski su u onom stajalištu prema kojem svakodnevna društvena i politička stvarnost generira toliko pitanja i problema da se intelektualci ne mogu i ne smiju dati potisnuti na marginu društva, već u njemu uvijek iznova moraju tražiti svoje mjesto i nišu za djelovanje. Iz toga proizlazi da su sve teme zapravo teme kulture, pa kada ona mora ući u političku sferu, to je za opću dobrobit društva i zajednice. Spomenimo usput, Taufer je od 1991. do 1995. godine bio savjetnik u vladi Republike Slovenije i jedan je od suautora Majniške deklaracije iz 1989. godine. Inače, njegov je javni kulturni i intelektualni angažman uglavnom određen kao opozicijski. Grafenauerovo polje javnog djelovanja prije svega je povezano s njegovim uređivanjem časopisa kao što su Problemi ili Ampak, dakako i Nova revija, dakle časopisa kojima se uobičajeno pripisuje velika uloga u demontaži bivšeg režima, pa su u tom smislu percipirani kao oporbeni. Upravo o oporbenjaštvu govori i Rudi Šeligo u prije spomenutom razgovoru u uredništvu Nove revije.

Nova revija od prvog je broja bila prije svega opozicijska (na nekim razinama subverzivna) a takva je i danas. Time ne mislim na konkretne ciljeve "mišljenja-pisanja-djelovanja" koji su osamdesetih godina bili obuhvaćeni pojmovima demokracija, normalizacija, samostalnost, nacija, osamostaljenje itd. Mislim na intelektualnu strukturu koja se, zapravo, nije promijenila, dakle, na unutarnji ustroj ili položaj mišljenja koji se izražava na stranicama Nove revije. ${ }^{19}$

U nastavku Šeligo naglašava kako je takav položaj mišljenja izvan bilo kakvih institucija ili političkih stranaka, jer ono kao opozicijsko mišljenje uvijek nastupa protiv većinskih struja.

Stvarima koje su političke naravi moguće je služiti na način realpolitike ili na način "mišljenja-postupanja" koje se pretjerano ne obazire na stvarne, pragmatične učinke od danas do sutra. Politika mogućeg je stvar države, njezinih organa i političkih stranaka. Politika "koja je više od onoga što jest” stvar je intelektualaca, pozicije intelektualnog mišljenja (koje je, dakako, već i postupanje, djelovanje). ${ }^{20}$

Kasnije će Šeligo još naglasiti, kako kaže, povijesnu nužnost da se zgrada slovenskoga kulturnog identiteta naseli te uz to nadodati, kao i većina njegovih sugovornika, činjenicu da je danas kultura na rubu društvenog interesa. ${ }^{21}$ Možda baš na tragu toga mogli bismo reći da je Šeligov javni intelektualni angažman prilično širokog raspona, od uredništva u utjecajnim, nazovimo ih (tada) oporbenim revijama (Revija 57, Perspektive, Problemi) do jednog od osnivača Slovenske demokratične zveze (1990. izabran je za zastupnika u parlamentu) i pozicije ministra za kulturu (srpanj 2000. - studeni 2000.).

Kao poticaj u pokušaju rezimiranja zaključno ću spomenuti Jančarev komentar u tom razgovoru, odnosno njegov prilično kritičan stav prema novorevijaškom krugu u vrijeme

\footnotetext{
18 Peter ZAJAC, "Intelektualci pet let pozneje: uspeh? brodolom? razočaranje?”, Nova revija, 14/1995., br. 163-164, $164-165$.

19 "Nova revija in izzivi časa”, 32.

20 Isto.

21 Isto, 33.
} 
tranzicije. Jančar, naime, kaže da je potreban pomak ne samo u državnom uređenju već i u mišljenju, a čini se da novorevijašima upravo to nije uspjelo: "Stari sadržaj, stari obrasci, stari modus vivendi, sve se je održalo." 22 Upravo ovo o čemu govori D. Jančar bila je, zapravo, okosnica većine kritika upućenih intelektualcima oko Nove revije. Tako, primjerice, Spomenka Hribar 2002. godine piše da se Nova revija u demokraciji nekako nije snašla, odnosno kao da nije pronašla svoj novi predmet interesa.

Nova revija još uvijek vodi borbu s komunizmom. (...) Kako komunizma kao sistema više nema ta se borba, ipso facto, odvija kao borba protiv komunista kao građana i ljudi. (...) Nova revija "vidi" samo komuniste kao apsolutne krivce za sve naše probleme u prošlosti i sadašnjosti (...) Nova revija je po mom razumijevanju slobode duha, što je bila njezina maksima od početka, previše identificirana s desnom političkom opcijom. ${ }^{23}$

Taj apriorni antikomunizam kritizirali su i drugi, među ostalim i Tine Hribar ili pak Gregor Tomc koji primjećuje kako u ono vrijeme antikomunizam nije toliko imao ideološki predznak koliko je bio sam po sebi ujedinjujući, ali se je ta nekada udružena opozicija fragmentirala i takav tadašnji antikomunizam postao je simbol desne političke opcije. ${ }^{24}$ Ono što je u tome bila ipak sretna okolnost, što se za hrvatsku intelektualnu sferu možda ne može reći, zanimljivo je primijetio Veno Taufer: velika povijesna sreća slovenskog nacionalizma - i intelektualaca koji su ga artikulirali - bila je ta da se odmah s politički pluralnom i samostalnom državnom realizacijom doslovno "izvukao". Nije degenerirao u državni nacionalizam. Jedan od uzroka, možda ključni, vjerojatno je upravo taj da se je nacionalna vlast ostvarila u istovremenu prijelazu više političkih kolona u prostor državnosti. ${ }^{25}$

Imajući sve ovo na umu, zaključujem uz malu pomoć Jeffreyja Goldfarba koji u svojoj knjizi Civility and Subversion: The Intellectual in Democratic Society ističe kako je za zapadne demokracije karakteristična politička marginalizacija intelektualaca, dapače, ona je na neki način prirodna, jer je mjesto intelektualaca premješteno u civilno društvo. U, nažalost, dobro nam poznatom srazu starih i novih elita te uz brojne izazove koje je tranzicija postavila pred intelektualce - pluralizacija medija, slobodno gospodarstvo, kritična percepcija prošlosti, izgradnja kulturnih institucija, otvaranje diskusija, poticanje društvenokritičnih analiza i alternativnih vizija politike itd. - kao da je ta možda najvažnija zadaća intelektualca u demokraciji, dakle aktivno sudjelovanje u civilnom društvu, blago rečeno, zanemarena.

No, možda u svemu tome ipak počiva barem neka, da parafraziram podnaslov poznate Fullerove knjige o intelektualcima, pozitivna moć negativnog mišljenja, sve do neke nove tranzicije.

\section{$\cos$}

\footnotetext{
Isto, 48 .

Spomenka Hribar, "Nova revija za prihodnost", Ampak, 3/2002., br. 6-7, 11-12.

"Nova revija in izzivi časa", 50.

V. TAUfER, "Slovenski intelektualec na poti iz 20. v 21. stoletje", 46.
} 


\section{The Intellectualism of Transition and the Transition of Intellectualism: the Example of the Nova REVIJA of LJubljana}

This paper describes the contributions of the Ljubljana paper Nova revija to intellectual activity and engagement in Slovenia of the 1980s and 1990s. It attempts to show how authors (primarily writers) understood their own position as intellectuals, the function and purpose of their work and its attempted scope. It analyzes published works and public appearances of authors like Niko Grafenauer, Rudi Šeligo, Marjan Rožanc, Dimitrij Rupel and Drago Jančar to show their views on the meaning and purpose of intellectual work during the period of transition and demonstrate, its contribution to current political events and the part it played in developing independent institutions and the (de)legitimization of the existing power structures at the time when Nova revija was founded, until now. Since the intellectuals (writers) which congregated around Nova revija held the traditionally privileged position of those whose role is to analyze social problems, the paper focuses on presenting (and understanding) their attempts to redefine their previous position of privileged advocates and preservers of national identity. Therefore, the paper shows the way they attempted to redefine their own role and the meaning of their public engagement in the newly created social and political circumstances of the 1990s.

Keywords: Nova revija, writers-intellectuals, transition, public engagement, culture and politics

\section{$\cos$}

\section{Literatura}

Jeffrey Goldfarb, Civility and subversion: The Intellectual in Democratic Society, Cambridge 1988. Niko Grafenauer, "Nova revija in izzivi časa”, Ampak, 3/2002., br. 6-7, 8-9.

Spomenka Hribar, "Nova revija za prihodnost”, Ampak, 3/2002., br. 6-7, 10-12.

Iztok KLEMENČıč, "Več kot le revija” (http://www.mladina.si/97608/).

Dean Komel, "Kritična beseda v tem času?” Dialogi, 38/2002., br. 3-4, 30-34.

Cvjetko Milanja, Čemu intelektualci u postmoderno doba, Zagreb 2011.

Bernard Nežмaн, "Slovenski intelektualec, literat-intelektualec in medijski intelektualec", Dialogi, 38/2002., br. 3-4, 35-37.

"Nova revija in izzivi časa”, Nova revija, 17/1998., br. 199-200, 1-53.

Dimitrij Rupel, "Nova revija, nov tednik, nova televizija”, Ampak, 3/2002., br. 6-7, 7-8.

Charles Percy SNOw, The two cultures and the scientific revolution, New York 1961.

Rok Svetrič, "Teza o prednosti literatov pri javnem angažmaju in družbeni vlogi”, Dialogi, 38/2002., br. 3-4, 38-43.

Veno TAufer, "Slovenski intelektualec na poti iz 20. v 21. stoletje”, Dialogi, 38/2002., br. 3-4, 44-48.

Matevž Tомšı̌̌, "Med kulturo in politiko: dileme vzhodno- in srednjeevropskih intelektualcev na poti “vračanja v Evropo"”, Nova revija, 22/2003., br. 252-253, 298-313.

Boris VEZJAK, "Uvodnik (Literati proti neliteratom: O javnem angažmaju in družbeni vlogi literatov-intelektualcev v primjeravi z neliterati-intelektualci)", Dialogi, 38/2002., br. 3-4, 18-20.

Peter ZAJAC, "Intelektualci pet let pozneje: uspeh? brodolom? razočaranje?”, Nova revija, 14/1995., br. $163-164,164-170$. 